\title{
Análisis de diversidad y estructura genética de poblaciones de Prosopis chilensis entre las provincias de Chacabuco y San Felipe de Aconcagua, usando marcadores moleculares microsatélites
}

\author{
Analysis of genetic diversity and differentiation of Prosopis chilensis populations between \\ Chacabuco and San Felipe de Aconcagua provinces using microsatellite molecular markers.
}

\author{
Roberto Contreras Díaz a*, Marlene González González ${ }^{\text {b }}$, \\ Fernanda Aguayo Cruces a, Sandra Gacitúa Arias ${ }^{b}$, Vincenzo Porcile Saavedra a
}

*Autor de correspondencia: ${ }^{a}$ Centro Regional de Investigación para el Desarrollo Sustentable de Atacama (CRIDESAT), Universidad de Atacama, Copayapu 485, Copiapó, Chile, fono 0056 522255407, roberto.contreras@uda.cl

${ }^{\mathrm{b}}$ Instituto Forestal (INFOR), Sede Metropolitana y Sede Diaguitas, Chile.

\begin{abstract}
SUMMARY
Prosopis chilensis is a native species of Chile distributed from Tarapacá Region to O'Higgins Region; however, despite its wide extension, the diversity, differentiation and genetic structure of its populations have not been studied. The objectives of the present study were to determine the level of genetic diversity and evaluate the genetic differentiation and population structure of $P$. chilensis from the central zone of Chile using seven microsatellite markers. A total of 53 alleles were detected among individuals of $P$. chilensis. The PIC value ranged from 0.057 (Mo05) to 0.847 (Mo16) with an average PIC of 0.636 . The expected heterozygosity averaged 0.610 and the observed heterozygosity averaged 0.588 . The inbreeding coefficient (FIS) for each population varied between 0.028 and 0.103 . The AMOVA analysis revealed that the greatest amount of genetic variation was found among individuals $(90.78 \%, P=0.0001)$ rather than among populations of $P$. chilensis $(0.16 \%, P=1.000)$. The level of genetic differentiation of $P$. chilensis was very low (FST $=$ 0.0015) among the four populations (LAPO, HUPE, ANDE and ENDO). The STRUCTURE analysis, the Mantel test and the EMD analysis indicate that all individuals are part of a single structure, there being no evidence of barriers that generate isolation. Therefore, in the future it will be necessary to carry out more population studies of this species, in such a way to detect variation and expand the genetic groups to maintain genetic richness and biodiversity of the ecosystems.
\end{abstract}

Key words: Algarobia section, microsatellite markers, conservation, low diversity, Fabaceae.

\section{RESUMEN}

Prosopis chilensis es una especie nativa de Chile distribuida desde la Región de Tarapacá hasta la Región del O’Higgins, sin embargo, a pesar de su amplia extensión, no se ha estudiado la diversidad, diferenciación y estructura genética de sus poblaciones. El objetivo del presente estudio fue determinar el nivel de diversidad genética, evaluar la diferenciación genética y estructura de poblaciones de $P$. chilensis de la zona central de Chile a partir de siete marcadores microsatélites. Un total de 53 alelos fueron detectados entre individuos de P. chilensis. El valor PIC varió desde 0,057 (Mo05) a 0,847 (Mo16) con un PIC promedio de 0,636. La heterocigosidad esperada tuvo un promedio de 0,610 y la heterocigosidad observada tuvo un promedio de 0,588 . El coeficiente de endogamia $\left(\mathrm{F}_{\mathrm{IS}}\right)$ para cada población varió entre 0,028 y 0,103. El análisis AMOVA reveló que la mayor cantidad de variación genética se encontró entre individuos $(90,78 \% ; P=0,0001)$ que entre poblaciones de $P$. chilensis $(0,16 \% ; P=1,000)$. El nivel de diferenciación genética de P. chilensis fue muy bajo $\left(\mathrm{F}_{\mathrm{ST}}=0,0015\right)$ entre las cuatro poblaciones (LAPO, HUPE, ANDE y ENDO). El análisis STRUCTURE, la prueba de Mantel y el análisis EMD indican que todos los individuos son parte de una sola estructura, no habiendo indicios de barreras que generen aislamiento. Por lo tanto, en el futuro será necesario realizar más estudios de población de esta especie, de tal manera de detectar variación y ampliar los grupos genéticos con el fin de mantener su riqueza genética y la biodiversidad de los ecosistemas.

Palabras clave: Algarobia section, microsatellite markers, conservation, low diversity, Fabaceae.

\section{INTRODUCCIÓN}

Prosopis chilensis (Mol.) Stuntz es una especie de algarrobo que según Ferreyra et al. (2010), presenta una amplia distribución, abarcando el sur del Perú, norte y centro de Chile, sudoeste de Bolivia y noroeste, oeste y centro de Argentina. Esta especie posee una extensa distribución en Chile, encontrándose desde la Región de Tarapacá hasta la Región de O'Higgins, pero, en la Región Metropolitana es donde se concentra más del $50 \%$ de la superficie nacional, 
con 11.828 hectáreas censado el año 2013 (González et al. 2017). Un estudio realizado por Aguilar et al. (2020) demostró que poblaciones de $P$. chilensis de Bolivia y Argentina presentarían haplotipos exclusivos, mostrando mayor diversidad molecular que las poblaciones chilenas, sugiriendo entonces una posible colonización o introducción desde estos países hacia Chile.

En la zona central de Chile, la especie crece naturalmente formando pequeños bosquetes o bien ejemplares aislados establecidos en valles o cuencas con napas freáticas relativamente superficiales y en fondos de quebradas (González et al. 2017). Se ha reconocido a los algarrobos como un importante recurso para la alimentación humana, como también trascendental para recuperar ecosistemas degradados y combatir la desertificación (Walter 2011). Desgraciadamente, su uso histórico no regulado para la obtención de leña, construcción de viviendas y carbón, ha significado una disminución de sus formaciones naturales (González et al. 2017). Actualmente se suma a ello, la presión de uso de suelos para fines inmobiliarios, especialmente en la Región Metropolitana, por ello se hace necesario generar información para su manejo, comenzando por estudios que permitan comprender la diversidad de la especie y la diferenciación de sus poblaciones, con el fin de apoyar la toma de decisiones para la elaboración y ejecución de planes de manejo de forestación y reforestación, especialmente en programas de restauración ecológica o a escala de paisaje.

Un estudio morfológico de poblaciones de $P$. chilensis demostró una escasa diferenciación genética en 17 poblaciones argentinas y seis poblaciones chilenas (Región de Coquimbo), crecidas y mantenidas en iguales condiciones de campo (Verzino et al. 2003). Estos autores señalaron que las semillas de $P$. chilensis utilizadas como muestras podrían ser de origen híbrido, debido al cruce frecuente entre P. chilensis y Prosopis flexuosa DC, sin embargo, no se realizó previamente una identificación genética de las muestras.

El análisis genético de poblaciones a partir de marcadores microsatélites (SSR, Short Sequence Repeats) son una buena alternativa comparado con otros marcadores de ADN, debido a que proporcionan alta tasa de polimorfismo, información útil para el estudio de la diversidad y diferenciación genética de poblaciones (Contreras et al. 2019), permiten la detección de cuellos de botella, flujo de genes, hibridación entre poblaciones y estructura de poblaciones (González 2003). Los microsatélites son marcadores codominantes, que consisten en secuencias cortas (de 1 a 6 bases de nucleótidos) repetidas en tándem, con una variación en el número de copias entre individuos (González 2003). Hasta la fecha varios loci SSR se han descubierto en especies de Prosopis, como en P. chilensis y P. flexuosa (Mottura et al. 2005, Bessega et al. 2013), Prosopis alba Griseb. (Bessega et al. 2013), Prosopis tamarugo Phil (Contreras et al. 2020); desarrollándose con estos marcadores varios estudios de diversidad y diferenciación genética de poblaciones (Mottura et al. 2005, 2018).
Prosopis chilensis es una especie con problemas de conservación en Chile, que habita zonas de clima árido, semiárido y mediterráneo, sin embargo, a pesar de su amplia extensión, no se ha estudiado su diversidad, diferenciación y estructura de poblaciones. La diferenciación genética entre poblaciones se relaciona con el grado de aislamiento o flujo de genes, siendo posible detectarlo con marcadores neutros como los SSR, de esta manera un reducido flujo de genes favorecería la diferenciación entre poblaciones, aumentando su homogeneidad (Bessega et al. 2018). La sección Algarobia a la cual pertenece $P$. chilensis, presenta una gran variación fenotípica con especies de la misma sección ( $P$. alba y $P$. flexuosa, entre otras), sin embargo, se ha observado una baja diferenciación genética y una frecuente hibridación entre ellas (Hunziker et al. 1986, Bessega et al. 2013). Para realizar estudios genéticos, se requiere de marcadores moleculares confiables que entreguen buena cantidad de información. Entre las especies de la serie Chilensis los marcadores SSR tienen una aceptable transferibilidad (Mottura et al. 2005, Bessega et al. 2013) para realizar estudios genéticos. En Chile, hasta ahora el único estudio de diversidad genética y estructura en $P$. chilensis a partir de marcadores SSR se ha realizado en poblaciones de la Región de Coquimbo (Moncada et al. 2019), sin embargo, aún no se ha estudiado la diversidad y estructura genética en poblaciones de $P$. chilensis de provincias de la zona central de Chile. Los objetivos del presente estudio son i) determinar el nivel de diversidad genética de poblaciones de $P$. chilensis a distintas zonas altitudinales y ii) evaluar la diferenciación y la estructura genética de poblaciones de dos provincias de la zona central de Chile a partir de marcadores SSR. La hipótesis propuesta es que en la zona central de Chile las poblaciones de $P$. chilensis presentan una alta diferenciación genética entre poblaciones y una alta diversidad genética debido a diferencias de distancia geográfica y altitud.

\section{MÉTODOS}

Material vegetal. Entre los meses de abril y mayo de 2018, se procedió a colectar hojas de 48 individuos de $P$. chilensis, desde distintas zonas de la Provincia de Chacabuco y la Provincia de San Felipe de Aconcagua, las cuales fueron agrupadas y georeferenciadas en cuatro poblaciones: Lampa-Polpaico (LAPO), Huechún-Peldehue (HUPE), Los Andes (ANDE) y Putaendo (ENDO) (cuadro 1, Apéndice 1). Los árboles fueron seleccionados al azar, dentro de las zonas de distribución de la especie (González 2013), en lo posible manteniendo una distancia mínima de 30 metros entre individuos, para evitar la relación de parentesco entre árboles. La muestra consistió en aproximadamente cien gramos de hojas jóvenes colectadas de la parte media de la copa de cada individuo, y de un largo mínimo de siete centímetros. Las muestras fueron inmediatamente guardadas en bolsas de polietileno y conservadas a $4{ }^{\circ} \mathrm{C}$ durante la jornada en terreno, para al final de cada día, ser guardado en congelador a $-20^{\circ} \mathrm{C}$, hasta su almacenamiento a $-80^{\circ} \mathrm{C}$. 
Cuadro 1. Localización geográfica de 48 individuos de Prosopis chilensis utilizados en este estudio.

Geographical location of 48 individuals of Prosopis chilensis used in this study.

\begin{tabular}{|c|c|c|c|c|c|c|}
\hline Provincia & Población & $\begin{array}{c}\text { Muestras } \\
\text { (n) }\end{array}$ & $\begin{array}{c}\text { Identificación } \\
\text { de muestras }\end{array}$ & $\begin{array}{l}\text { Longitud } \\
\text { (S) }\end{array}$ & $\begin{array}{l}\text { Latitud } \\
\text { (W) }\end{array}$ & $\begin{array}{l}\text { Elevación } \\
\text { (m s.n.m.) }\end{array}$ \\
\hline \multirow{2}{*}{ Chacabuco } & Lampa-Polpaico (LAPO) & 8 & $1-8$ & $33^{\circ} 15^{\prime} 56,568^{\prime \prime}$ & $70^{\circ} 53^{\prime} 37,811^{\prime \prime}$ & 483 \\
\hline & Huechún-Peldehue (HUPE) & 19 & $9-27$ & $33^{\circ} 8^{\prime} 49,789^{\prime \prime}$ & $70^{\circ} 39^{\prime} 35,417^{\prime \prime}$ & 719 \\
\hline \multirow{2}{*}{$\begin{array}{l}\text { San Felipe de } \\
\text { Aconcagua }\end{array}$} & Los Andes (ANDE) & 15 & $28-42$ & $32^{\circ} 49^{\prime} 59,14^{\prime \prime}$ & $70^{\circ} 34^{\prime} 4,846^{\prime \prime}$ & 875 \\
\hline & Putaendo (ENDO) & 6 & $43-48$ & $32^{\circ} 34^{\prime} 52,855^{\prime \prime}$ & $70^{\circ} 42^{\prime} 0,783^{\prime \prime}$ & 925 \\
\hline
\end{tabular}

Extracción de ADN. El ADN genómico se extrajo utilizando la metodología descrita por Contreras et al. (2019), como se indica a continuación: para la lisis celular, 100 $\mathrm{mg}$ de polvo fino de hojas jóvenes, $14 \mu \mathrm{L}$ de beta-mercaptoetanol, $14 \mu \mathrm{L}$ de $10 \mathrm{mg} \mathrm{mL}^{-1}$ de proteinasa $\mathrm{K}, 14 \mu \mathrm{L}$ de Sarkosyl al 5 \%, 0,045 g de D-sorbitol (MW 182,17 $\mathrm{g} \mathrm{mol}^{-}$ $\left.{ }^{1}\right)$ y se añadieron a cada tubo $700 \mu \mathrm{L}$ de CTAB precalentado a $65{ }^{\circ} \mathrm{C}$ durante 15 minutos ( $4 \%$ p/v PVP-40, Tris- $\mathrm{HCl}$ $100 \mathrm{mM}, \mathrm{pH}$ 8; $\mathrm{NaCl} 1,2 \mathrm{M}$; EDTA $20 \mathrm{mM}$, CTAB al 2 $\%)$. Se agitaron con un vórtex y luego se incubaron en un baño de agua durante 60 minutos a $65^{\circ} \mathrm{C}$, invirtiendo los tubos cada 15 minutos. Luego, los tubos se centrifugaron a $14.000 \mathrm{rpm}$ durante 15 minutos a $4{ }^{\circ} \mathrm{C}$, y se recuperó la fase acuosa superior $(\sim 700 \mu \mathrm{L})$ y se vertió a un tubo nuevo. Posteriormente, se agregaron $800 \mu \mathrm{L}$ de solución de fenol/cloroformo/alcohol isoamílico UltraPure ${ }^{\mathrm{TM}}$ (25: 24: 1) a cada tubo y se mezcló durante 10 minutos a $120 \mathrm{rpm}$ en un incubador-agitador a $20^{\circ} \mathrm{C}$. Luego, estos tubos se centrifugaron a $14.000 \mathrm{rpm}$ durante 15 minutos a $4{ }^{\circ} \mathrm{C}$ y la fase superior se recuperó para un procesamiento adicional $(\sim 550 \mu \mathrm{L})$, intentando no perturbar la fracción inferior del tubo. Este sobrenadante fue transferido a un nuevo tubo. A continuación, se agregaron $8 \mu \mathrm{L}$ de $10 \mathrm{mg} \mathrm{mL}^{-1}$ de RNAsa a cada tubo, seguido de incubación a $55^{\circ} \mathrm{C}$ durante $8 \mathrm{~min}$. Se agregaron dos tercios de isopropanol a $-20{ }^{\circ} \mathrm{C}$ a los tubos $(367 \mu \mathrm{L}$ de isopropanol para $550 \mu \mathrm{L}$ de solución en este caso), que luego se invirtieron 30 veces a temperatura ambiente para revolver la mezcla. El líquido se transfirió luego a una mini columna Hi-Bind DNA (Omega Bio-tek) unida a un tubo de recolección de $2 \mathrm{~mL}$ y se dejó incubar durante 2 minutos a temperatura ambiente. Las mini columnas se centrifugaron a $14.000 \mathrm{rpm}$ durante 2 minutos y luego se eliminó el precipitado. Luego se lavó con $700 \mu \mathrm{L}$ de etanol al $90 \%$ a temperatura ambiente, se centrifugaron a 14.000 rpm durante 2 minutos y se desechó el precipitado. A esto le siguió la adición de $700 \mu \mathrm{L}$ de etanol al 70 $\%$ con $\mathrm{NH}_{4} \mathrm{OAc}[10 \mathrm{mM}]$ a temperatura ambiente, centrifugación a $14.000 \mathrm{rpm}$ durante 2 minutos y se descartó el precipitado. Las mini columnas vacías se centrifugaron a $14.000 \mathrm{rpm}$ durante 2 minutos para eliminar el etanol restante y el tubo de recolección se reemplazó por un nuevo tubo de 1,5 mL. Luego, se agregó $60 \mu \mathrm{L}$ de TE precalentado a $65^{\circ} \mathrm{C}$ a cada mini columna, seguido de incubación a $65^{\circ} \mathrm{C}$ durante 5 minutos. Finalmente, los tubos se centrifugaron a $14.000 \mathrm{rpm}$ durante 2 minutos, la mini columna se descartó y el tubo de $1,5 \mathrm{~mL}$ con el extracto se almacenó a $-20{ }^{\circ} \mathrm{C}$ para su posterior uso. La calidad y la concentración total de ADN se verificó con un espectrofotómetro Colibri Microvolume (Titertek Berthold, Alemania) a 260, 280 y $230 \mathrm{~nm}$. La integridad del ADN genómico se verificó en un gel de agarosa al 0,7\% (el tiempo de electroforesis fue de $40 \mathrm{~min}$ a $100 \mathrm{~V}$ ).

Amplificación marcadores SSR. Para la amplificación de los marcadores microsatélites (SSR) neutros se utilizaron parejas de cebadores detallados en el cuadro 2, descritos por Mottura et al. (2005) y Bessega et al. (2013). Para obtener los alelos de individuos de $P$. chilensis, se dispusieron reacciones de PCR con cada pareja de cebador SSR. Se prepararon reacciones de PCR con un volumen total de 20 $\mu \mathrm{L}$ como se describe a continuación: $10 \mu \mathrm{L}$ de Master Mix SapphireAmp Fast PCR 2X (Takara-Clontech), $4 \mu \mathrm{L}$ de ADN genómico $\left(5 \mathrm{ng} \mu \mathrm{L}^{-1}\right), 1 \mu \mathrm{L}$ de cada cebador forward y reverse (a una concentración de $5 \mu \mathrm{M}$ ), y $4 \mu \mathrm{L}$ de agua libre de nucleasas. Las amplificaciones se realizaron en un termociclador Labnet MultiGene OptiMax con las siguientes condiciones: un paso inicial de 4 minutos a $94^{\circ} \mathrm{C}$, 30 ciclos de 45 segundos a $94^{\circ} \mathrm{C}, 45$ segundos de temperatura de anillamiento (Ta) (ver cuadro 2) y 45 segundos a 72 ${ }^{\circ} \mathrm{C}$, seguido por un paso de extensión final de 10 minutos a $72{ }^{\circ} \mathrm{C}$. Para la detección de los alelos (por electroforesis capilar), los cebadores forward se marcaron con un fluoróforo 5'-FAM y 5' HEX y los productos de PCR fueron obtenidos con un analizador genético ABI3730XL (Applied Biosystems); para comprobar el tamaño de los alelos se utilizó un marcador estándar Gene Scan ${ }^{\mathrm{TM}} 400 \mathrm{HD}^{\mathrm{TM}}$ Rox (Applied Biosystems). Los tamaños de los alelos se observaron y registraron mediante el software Peak Scanner (Applied Biosystems, versión 1.0).

Análisis de datos. Se analizó la posibilidad de detectar alelos nulos en cada locus usando el programa MICROCHECKER v.2.2.3 (Van Oosterhout et al. 2004). Para cada población y locus se evaluó el equilibrio de Hardy-Weinberg (HWE), y desequilibrio de ligamiento (LD) entre todos los pares de loci utilizando el software Arlequin v. 3.1 
Cuadro 2. Descripción de cebadores microsatélites usados en cuatro poblaciones de Prosopis chilensis.

Description of microsatellite primers used in four populations of Prosopis chilensis.

\begin{tabular}{|c|c|c|c|c|}
\hline Locus & Secuencia ADN $\left(5^{\prime}-3^{\prime}\right)$ y fluoróforo (FAM, HEX) & Motivo & $\mathrm{Ta}\left({ }^{\circ} \mathrm{C}\right)$ & Referencias \\
\hline GL8 & $\begin{array}{l}\text { F: 5'-FAM-CAGGTGGGCATGAAGTTTCC-3' } \\
\text { R: 5'-CCAAGAACAACCTGCCGAAG-3' }\end{array}$ & $(\mathrm{AT})_{12}$ & 58 & Bessega et al. (2013) \\
\hline GL21 & $\begin{array}{l}\text { F:5'-HEX-ATCTCCGTCACAACTTGCAC-3' } \\
\text { R:5'-ACCCTCACTCCCGAATGATG-3' }\end{array}$ & $(\mathrm{AG})_{5}$ & 58 & Bessega et al. (2013) \\
\hline Mo13 & $\begin{array}{l}\text { F:5'-FAM-TTGATTAGAGTTGCATGTGGATG-3' } \\
\text { R:5'-TGCAGTCCCAAGTGTCAGAG-3' }\end{array}$ & $(\mathrm{GT})_{10} \mathrm{CT}(\mathrm{GT})_{2}$ & 58 & Mottura et al. (2005) \\
\hline GL15 & $\begin{array}{l}\text { F: 5'-FAM-GTGTTATGGTCCCAACAGCC-3' } \\
\text { R: 5'-TGAAGAGGGAGGAATCGCAG-3' }\end{array}$ & $(\mathrm{AG})_{12}$ & 58 & Bessega et al. (2013) \\
\hline Mo08 & $\begin{array}{l}\text { F: 5'-HEX-TATCCTAAACGCCGGGCTAC-3' } \\
\text { R: 5'-TCCCATTCATGCATACTTAAACC-3' }\end{array}$ & $(\mathrm{AC})_{9}$ & 59 & Mottura et al. (2005) \\
\hline Mo16 & $\begin{array}{l}\text { F:5'-FAM-CATTGCCCCAATATCACTCC-3' } \\
\text { R: 5'-GGGTCCATCCAGAGTAGTGG-3' }\end{array}$ & $(\mathrm{CA})_{32}$ & 60 & Mottura et al. (2005) \\
\hline Mo05 & $\begin{array}{l}\text { F:5'-HEX-AATTCTGCAGTCTCTTCGCC-3' } \\
\text { R:5'-GATCCCTCGTGACTCCTCAG-3' }\end{array}$ & $(\mathrm{CT})_{3} \mathrm{~T}(\mathrm{CT})_{2}$ & 64 & Mottura et al. (2005) \\
\hline
\end{tabular}

(Excoffier et al. 2005) y FSTAT v. 2. 9.3 (Goudet 2001). El HWE se evaluó usando 10.000 iteraciones de simulación y la prueba de LD se llevó a cabo con 9.999 permutaciones. Se calculó el número total de alelos por locus $(\mathrm{Na})$, número efectivo de alelos $(\mathrm{Ne})$, heterocigosidad observada (Ho), heterocigosidad esperada (He), alelo privado (AP), el índice de diversidad de Shannon (I) y los parámetros estadísticos $\mathrm{F}$ de Wright $\left(\mathrm{F}_{\mathrm{IS}}, \mathrm{F}_{\mathrm{IT}}\right.$ y $\mathrm{F}_{\mathrm{ST}}$ ) utilizando el software FSTAT v. 2. 9.3 (Goudet 2001) y Arlequin v. 3.1 (Excoffier et al. 2005). Los valores de $\mathrm{F}_{\mathrm{ST}}$ de la población por pares se realizaron en 1.000 permutaciones. El contenido de información polimórfica (PIC) para cada locus SSR se estimó mediante la fórmula: $\mathrm{PIC}=1-\Sigma \mathrm{pi}^{2}$, donde $p i$ son las frecuencias de los diferentes alelos detectados en el locus. Para estimar la variabilidad genética dentro y entre las poblaciones se calculó el análisis no paramétrico de la prueba de la varianza molecular (AMOVA) usando GenAlex v. 6.5 (Peakall y Smouse 2012) con 1.000 permutaciones. Como técnica de análisis de grupos, se realizó un análisis multivariado mediante Escalamiento Multidimensional (EMD) utilizando el programa PAST (Hammer et al. 2001).

Se evaluó el aislamiento por distancia mediante la prueba de Mantel entre las distancias genéticas y distancias geográficas utilizando el software GenAlex v. 6.5 (Peakall y Smouse 2012), llevándose a cabo con 1.000 permutaciones. La estructura genética de los 48 individuos de $P$. chilensis se determinó mediante un análisis de conglomerado bayesiano, utilizando el software STRUCTURE v.2.3 (Pritchard et al. 2000). Para el análisis, se usó un modelo de mezcla con frecuencias alélicas correlacionadas sin la opción LocPrior. El número óptimo de subpoblaciones $(\mathrm{K})$ se identificó después de tres ejecuciones independientes para cada valor " $\mathrm{K}$ " que osciló entre 1 y 4, con un período burn-in de 200.000 repeticiones, seguido de repeticiones de Markov Chain Monte Carlo (MCMC) de 350.000 repeticiones. Fueron examinados dos criterios con valores medios de probabilidad logarítmica: $\mathrm{L}(\mathrm{K})$ y delta $\mathrm{K}(\Delta \mathrm{K})$, para encontrar los valores apropiados de K. Se procesaron los datos para identificar los grupos óptimos (K) utilizando el programa web STRUCTURE HARVESTER (Earl y Vonholdt 2012).

\section{RESULTADOS}

Una prueba de desequilibrio de ligamiento (LD) para cada población detectó una desviación de equilibrio significativa en 5 de 56 combinaciones de loci, con un nivel de significancia del $5 \%$. Sin embargo, ninguno de estos pares de loci SSR con desequilibrio de ligamiento fue significativo después de aplicada la corrección de Bonferroni. En todos los loci hubo ausencia de alelos nulos, aplicando el programa MICRO-CHECKER. Un total de 53 alelos fueron detectados entre los individuos de $P$. chilensis. El número de alelos generados por cada marcador SSR varió de 2 a 11 con un promedio de 7,5 alelos por locus (cuadro 3). El mayor número de alelos se observó en el locus Mo16 (11 alelos) y el menor número de alelos se observó en el locus Mo05 (2 alelos) (cuadro 3). El tamaño de los fragmentos amplificados osciló entre 168 a 200 pb (GL8), 214 a 234 pb (GL21), 218 a 240 pb (Mo13), 194 a 216 pb (GL15), 214 a $222 \mathrm{pb}$ (Mo08), 145 a $165 \mathrm{pb}$ (Mo16) y 216 a $218 \mathrm{pb}$ (Mo05). El valor PIC estuvo en el rango de 0,057 (Mo05) a 0,847 (Mo16) con un PIC medio de 0,636 para todos los loci (cuadro 3). El número efectivo de alelos para cada locus varió de 1,063 a 5,821, con un promedio de 3,446 . La heterocigosidad esperada osciló entre 0,820 en el locus Mo16 y 0,056 en el locus Mo05, con un promedio 
de 0,610 para todos los loci. La heterocigosidad observada varió de 0,801 en el locus Mo13 a 0,000 en el locus Mo05, con un promedio de 0,588 para todos los loci (cuadro 3). Se detectó una significativa $(P<0,05)$ desviación del equilibrio de Hardy-Weinberg (HWE) en los loci Mo16 y Mo05 en la mayoría de las poblaciones, y una significativa desviación de HWE $(P<0,1)$ del locus Mo18 en la población ENDO. El coeficiente de endogamia (FIS) varió desde $-0,171$ (Mo13) a 1,000 (Mo05), con un promedio de 0,156 para todos los loci. La diferenciación genética (FST) de los loci individuales varió de 0,026 (GL15) hasta 0,074 (Mo13), y promedió un valor de 0,042 para todos los loci. Por otro lado, el coeficiente de endogamia total (FIT) varió desde $-0,084$ (Mo13) a 1,000 (Mo05), con un promedio de 0,194 para todos los loci (cuadro 3).

Se observaron alelos privados exclusivos para las poblaciones HUPE $(\mathrm{AP}=5)$, $\mathrm{LAPO}(\mathrm{AP}=4)$ y $\mathrm{ANDE}(\mathrm{AP}=3)$, pero no se encontraron en la población ENDO (cuadro 4). El índice de Shannon (I) varió entre 1,101 en la población ENDO a 1,360 en la población HUPE. El valor más alto de Ho $=0,642 \pm 0,301$ se observó en LAPO, mientras que el valor más bajo se encontró en la población ANDE $(\mathrm{Ho}=$ $0,514 \pm 0,232)$. El valor de He estimado más alto dentro se detectó en población LAPO $(0,660 \pm 0,307)$, mientras que el valor más bajo se detectó en $\operatorname{ANDE}(0,629 \pm 0,231)$. Para todas las poblaciones analizadas, la heterocigosidad promedio observada fue menor que la heterocigosidad esperada

El coeficiente de endogamia $\left(\mathrm{F}_{\text {IS }}\right)$ para cada población varió entre 0,028 y 0,103 , lo que indica en general una deficiencia de heterocigotos, y se encontró un significativo $\mathrm{F}_{\mathrm{IS}}\left(\mathrm{F}_{\mathrm{IS}}=0,188 ; P<0,001\right)$ en la población ANDE. El valor de $\mathrm{F}_{\mathrm{ST}}$ osciló en $-0,023$ y 0,024 para las poblaciones LAPO y ANDE, respectivamente (cuadro 4). Los valores de diferenciación genética se calcularon entre pares de poblaciones, donde hubo una baja diferenciación genética $\left(\mathrm{F}_{\mathrm{ST}}=0,030\right)$ significativa $(P<0.05)$ solo entre las poblaciones HUPE y LAPO (cuadro 5).

El análisis AMOVA reveló que la mayor cantidad de variación genética se encontró entre los individuos $(90,78 \%$; $P=0,0001$, y una muy baja variación genética entre poblaciones de $P$. chilensis $(0,16 \% ; P=1,000)$, lo que demuestra una baja diferenciación genética entre las cuatro poblaciones $\left(\mathrm{F}_{\mathrm{ST}}=0,0015 ; P=1,000\right)$ (cuadro 6 ). El promedio de coeficiente de endogamia $\left(\mathrm{F}_{\mathrm{IS}}\right)$ y el coeficiente de endogamia total $\left(\mathrm{F}_{\text {ITT }}\right)$ fue significativo, cuyos valores fueron 0,0907

Cuadro 3. Estadísticas de diversidad de siete loci SSR utilizados en 48 individuos de Prosopis chilensis.

Diversity statistics of seven SSR loci used in 48 individuals of Prosopis chilensis.

\begin{tabular}{lcccccccc}
\hline Locus & $\mathrm{Na}$ & $\mathrm{PIC}$ & $\mathrm{Ne}$ & $\mathrm{Ho}$ & $\mathrm{He}$ & $\mathrm{F}_{\mathrm{IS}}$ & $\mathrm{F}_{\mathrm{ST}}$ & $\mathrm{F}_{\mathrm{IT}}$ \\
\hline GL8 & 10 & 0,778 & $4,173( \pm 0,592)$ & $0,789( \pm 0,072)$ & $0,740( \pm 0,048)$ & $-0,066 \mathrm{~ns}$ & $0,049 \mathrm{~ns}$ & $-0,014 \mathrm{~ns}$ \\
GL21 & 7 & 0,625 & $2,629( \pm 0,323)$ & $0,672( \pm 0,054)$ & $0,604( \pm 0,042)$ & $-0,113 \mathrm{~ns}$ & $0,033 \mathrm{~ns}$ & $-0,076 \mathrm{~ns}$ \\
Mo13 & 8 & 0,738 & $3,329( \pm 0,425)$ & $0,801( \pm 0,128)$ & $0,684( \pm 0,041)$ & $-0,171 \mathrm{~ns}$ & $0,074 *$ & $-0,084 \mathrm{~ns}$ \\
GL15 & 10 & 0,794 & $4,525( \pm 0,368)$ & $0,793( \pm 0,017)$ & $0,774( \pm 0,020)$ & $-0,024 \mathrm{~ns}$ & $0,026 \mathrm{~ns}$ & $0,002 \mathrm{~ns}$ \\
Mo08 & 5 & 0,618 & $2,581( \pm 0,342)$ & $0,500( \pm 0,062)$ & $0,588( \pm 0,063)$ & $0,150 * *$ & $0,049 \mathrm{~ns}$ & $0,192 * *$ \\
Mo16 & 11 & 0,847 & $5,821( \pm 0,762)$ & $0,562( \pm 0,088)$ & $0,820( \pm 0,020)$ & $0,315 * * *$ & $0,032 \mathrm{~ns}$ & $0,337 * * *$ \\
Mo05 & 2 & 0,057 & $1,063( \pm 0,037)$ & $0,000( \pm 0,000)$ & $0,056( \pm 0,033)$ & $1,000 * * *$ & $0,032 \mathrm{~ns}$ & $1,000 * * *$ \\
\hline Promedio & 7,5 & 0,636 & 3,446 & 0,588 & 0,610 & 0,156 & 0,042 & 0,194 \\
& $( \pm 0,037)$ & $( \pm 0,258)$ & $( \pm 0,316)$ & $( \pm 0,056)$ & $( \pm 0,048)$ & $( \pm 0,154)$ & $( \pm 0,006)$ & $( \pm 0,146)$ \\
\hline
\end{tabular}

$P$-valor: $* P<0,10 ; * * P<0,05 ; * * * P<0,0001 ; \mathrm{ns}=$ no significativo.

Cuadro 4. Estadística de diversidad de cuatro poblaciones de Prosopis chilensis. Statistics of diversity of four populations of Prosopis chilensis.

\begin{tabular}{ccccccccc}
\hline Población & $\mathrm{n}$ & $\mathrm{Ap}$ & $\mathrm{I}$ & $\mathrm{Ho}$ & $\mathrm{He}$ & $\mathrm{F}_{\mathrm{IS}}$ & $\mathrm{F}_{\mathrm{ST}}$ \\
\hline LAPO & 8 & 4 & $1,327( \pm 0,275)$ & $0,642( \pm 0,301)$ & $0,660( \pm 0,307)$ & $0,028 \mathrm{~ns}$ & $-0,023 \mathrm{~ns}$ \\
HUPE & 19 & 5 & $1,360( \pm 0,220)$ & $0,624( \pm 0,276)$ & $0,647( \pm 0,239)$ & $0,037 \mathrm{~ns}$ & $-0,004 \mathrm{~ns}$ \\
ANDE & 15 & 3 & $1,288( \pm 0,212)$ & $0,514( \pm 0,232)$ & $0,629( \pm 0,231)$ & $0,188 * *$ & $0,024 \mathrm{~ns}$ \\
ENDO & 6 & 0 & $1,101( \pm 0,196)$ & $0,571( \pm 0,331)$ & $0,632( \pm 0,267)$ & $0,104 \mathrm{~ns}$ & $0,020 \mathrm{~ns}$ \\
\hline
\end{tabular}

$P$-valor: $* P<0,10 ; * * P<0,001 ; \mathrm{ns}=$ no significativo. 
( $P<0,01)$ y 0,0921 ( $P<0,0001)$, respectivamente (cuadro 6). El análisis multivariado EMD mostró un solo agrupamiento, encontrándose mezclados individuos de $P$. chilensis de distintas poblaciones (figura 1). Usando la prueba de Mantel, se observó que los 48 individuos de $P$. chilensis presentaron ausencia de correlación entre la distancia genética y la distancia geográfica $\left(\mathrm{r}^{2}=0,0001 ; P=0,480\right)$, no revelando aislamiento por distancia (figura 2). En cuanto al análisis de estructura genética, para encontrar el valor $\mathrm{K}$ real se usaron dos criterios: en la figura $3 \mathrm{~A}$ se puede observar el valor máximo $\mathrm{L}(\mathrm{K}) \mathrm{K}=1$ que luego en las siguientes simulaciones disminuyó notablemente con una alta varianza entre ejecuciones; por otro lado, de acuerdo al otro criterio, se pudo observar un $\Delta \mathrm{K}$ alto, con un valor $\mathrm{K}=3$ en la figura 3B. En la figura 4 se observa la estructura de individuos de $P$. chilensis con un valor $\mathrm{K}=3$, mostrando una misma estructura para todas las poblaciones.

\section{DISCUSIÓN}

El presente estudio evalúa la variabilidad genética y diversidad de poblaciones de $P$. chilensis de dos provincias de la zona central de Chile, dado que se reconoce como la zona de mayor distribución de esta especie. Los resultados basados en análisis de 48 individuos de $P$. chilensis a partir de siete loci SSR muestran una moderada diversidad y una baja diferenciación genética entre poblaciones de la Pro-

Cuadro 5. Valores $\mathrm{F}_{\mathrm{ST}}$ de diferenciación genética por pares entre cuatro poblaciones de Prosopis chilensis.

Pairwise $\mathrm{F}_{\mathrm{ST}}$ values of genetic differentiation from four Prosopis chilensis populations.

\begin{tabular}{lcccc}
\hline & LAPO & HUPE & ANDE & ENDO \\
\hline LAPO & - & & & \\
HUPE & $0,030^{* *}$ & - & & \\
ANDE & $0,025 \mathrm{~ns}$ & $-0,008 \mathrm{~ns}$ & - & \\
ENDO & $-0,010 \mathrm{~ns}$ & $-0,003 \mathrm{~ns}$ & $0,0003 \mathrm{~ns}$ & - \\
\hline
\end{tabular}

$P$-valor: $* * P<0,05 ;$ ns $=$ no significativo. vincia de Chacabuco y San Felipe de Aconcagua. En este estudio seis loci microsatélites muestran un alto polimorfismo, sin embargo, un bajo polimorfismo se observa en un locus (Mo05). De acuerdo a Mottura et al. (2005), el locus Mo05 también muestra bajo polimorfismo en $P$. chilensis, revelando solo tres alelos en 20 individuos del Chaco de Argentina, mientras en la presente investigación se confirman dos alelos en 48 individuos. Por el contrario, Moncada et al. (2019) en poblaciones de P. chilensis de la Región de Coquimbo evidenciaron, en general, más alelos que en nuestro estudio, observando 10 alelos en el locus Mo08, 8 alelos en el locus Mo13 y 5 alelos en el locus Mo05, este último con un rango de 204 a 216 pb, presenta un pseudogen (alelo 204), debido a que el mínimo tamaño de este fragmento es de $209 \mathrm{pb}$. Por otro lado, el estudio de Mottura et al. (2005) encontró cinco alelos en el locus Mo16, mientras que en el presente trabajo se detecta 11 alelos, sin embargo, se analiza un número mayor de individuos comparado con el trabajo de Mottura et al. (2005). En cuanto a los microsatelites exhibidos por Bessega et al. (2013), usando hasta 10 individuos de $P$. chilensis, estos autores descubrieron 6, 4 y 2 alelos con los loci GL8, GL15 y GL21, respectivamente, mientras que en el presente estudio se detecta 10,10 y 7 con los mismos loci, respectivamente, encontrando, por lo tanto, mayor cantidad de alelos en las poblaciones chilenas.

De acuerdo a Mottura et al. (2005), P. chilensis y $P$. flexuosa son especies que están estrechamente relacionadas. Por lo mismo y debido a que hay escasos estudios genéticos de poblaciones de $P$. chilensis, se podría usar como medio de comparación información de la especie $P$. flexuosa. En poblaciones de $P$. chilensis del presente estudio se observa en promedio 7,5 alelos usando siete loci SSR, mientras que (Bessega et al. 2017) en poblaciones de $P$. flexuosa obtuvieron 7,9 alelos promedio de 8 loci SSR; cabe indicar que entre los dos estudios hay cuatro loci afines (Mo08, GL21, GL15 y Mo13). Además, los valores PIC de loci SSR observadas en esta investigación ( in considerar Mo05) con P. chilensis son altas (valores desde 0,625 a 0,794 para los SSR-GL; desde 0,618 a 0,847 para los SSR-Mo) comparado con los descritos por Bessega et al. (2013) con valores entre 0,37 a 0,70 (GL8, GL15 y GL21), Moncada et al. (2019) con valores entre 0,49 a

Cuadro 6. Análisis de varianza molecular (AMOVA) para cuatro poblaciones de Prosopis chilensis.

Molecular variance analysis (AMOVA) for four populations of Prosopis chilensis.

\begin{tabular}{lcccccc}
\hline Fuente de variación & gl & $\begin{array}{c}\text { Suma de } \\
\text { cuadrados }\end{array}$ & $\begin{array}{c}\text { Componentes } \\
\text { de varianza }\end{array}$ & $\begin{array}{c}\text { Porcentaje } \\
\text { de variación }\end{array}$ & $\begin{array}{c}\text { Indices de } \\
\text { fijación }\end{array}$ & $\begin{array}{c}P \text {-valor } \\
\text { Entre poblaciones }\end{array}$ \\
Entre individuos dentro de poblaciones & 44 & 7,622 & 0,00351 & 0,16 & FST $=0,0015$ & 1,0000 \\
Entre individuos & 48 & 98,500 & 2,05208 & 90,78 & FIT $=0,0921$ & 0,0001 \\
\hline Total & 95 & 214,438 & 2,26041 & & & \\
\hline
\end{tabular}

Description of microsatellite primers used in four populations of Prosopis chilensis. 
0,68 (Mo08, Mo09 y Mo13) y Mottura et al. (2005) con valores entre 0,48 a 0,70 (Mo08, Mo13 y Mo16).

La diversidad genética de $P$. chilensis con respecto a la heterocigosidad esperada (He) promedio en tres loci (Mo08, Mo13 y Mo16) en individuos del Chaco Argentino (Mottura et al. 2005) y la zona central de Chile $(0,636$ y 0,697 , respectivamente) es mayor en los individuos de la zona central de Chile que la región de Argentina. Sin embargo, si se incluye en el cálculo el locus Mo05, la di- versidad es mayor en el Chaco Argentino. Por otro lado, si se compara entre especies afines, como P. flexuosa y $P$. chilensis, la media de la heterocigosidad esperada (He) usando cuatro loci (GL15, Mo08, GL21 y Mo13), se obtiene 0,70 (Bessega et al. 2017) y 0,66, respectivamente; siendo levemente mayor la diversidad genética de $P$. flexuosa que $P$. chilensis. Este resultado de mayor predominio de variación genética en $P$. flexuosa que $P$. chilensis también es constatado por Motura et al. (2005).

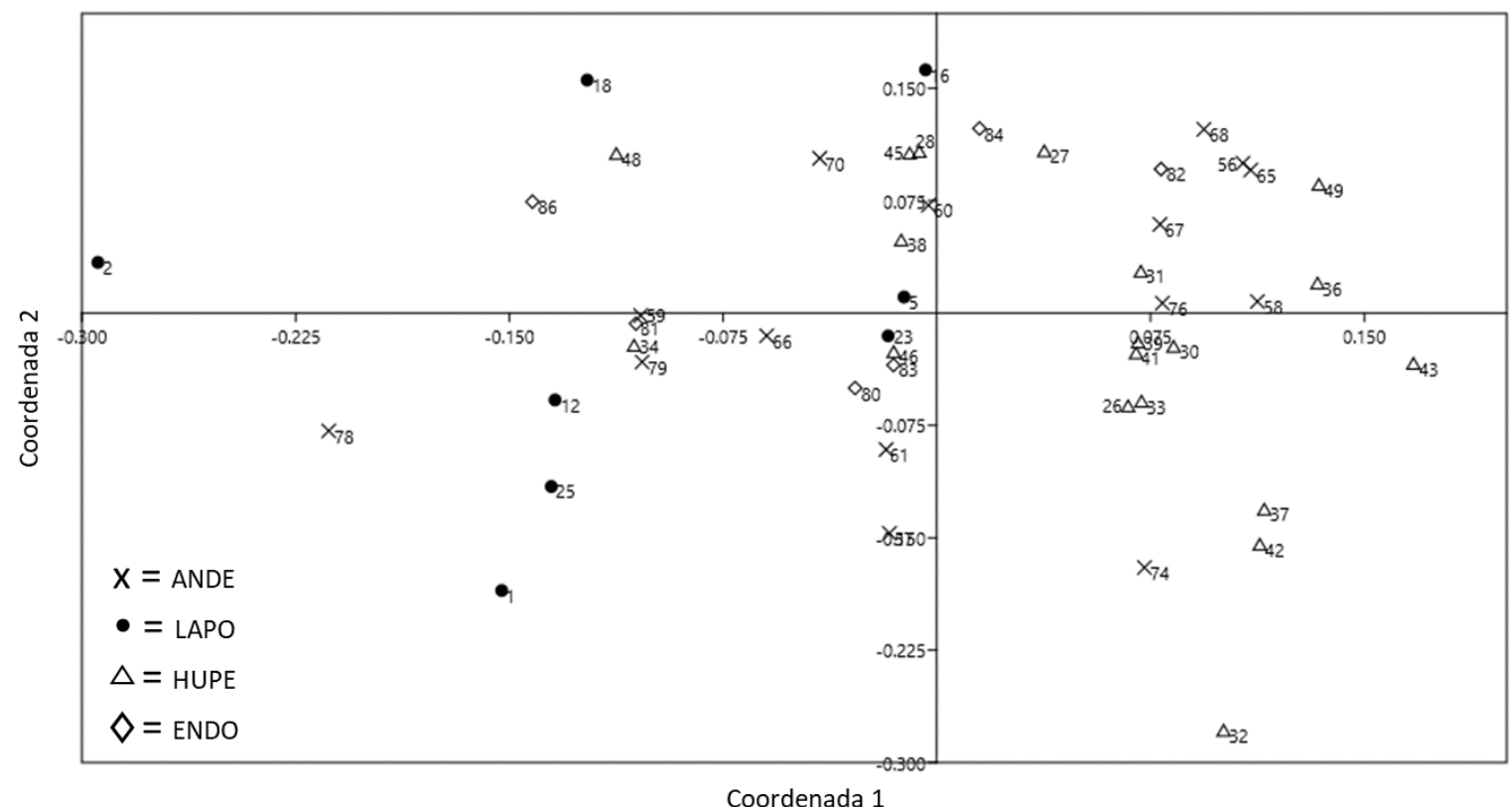

Figura 1. Análisis de Escalamiento Multidimensional (EMD) de 48 individuos de Prosopis chilensis, usando siete marcadores SSR Analysis of Multidimensional Scaling (MDS) of 48 individuals of Prosopis chilensis, using seven SSR markers.

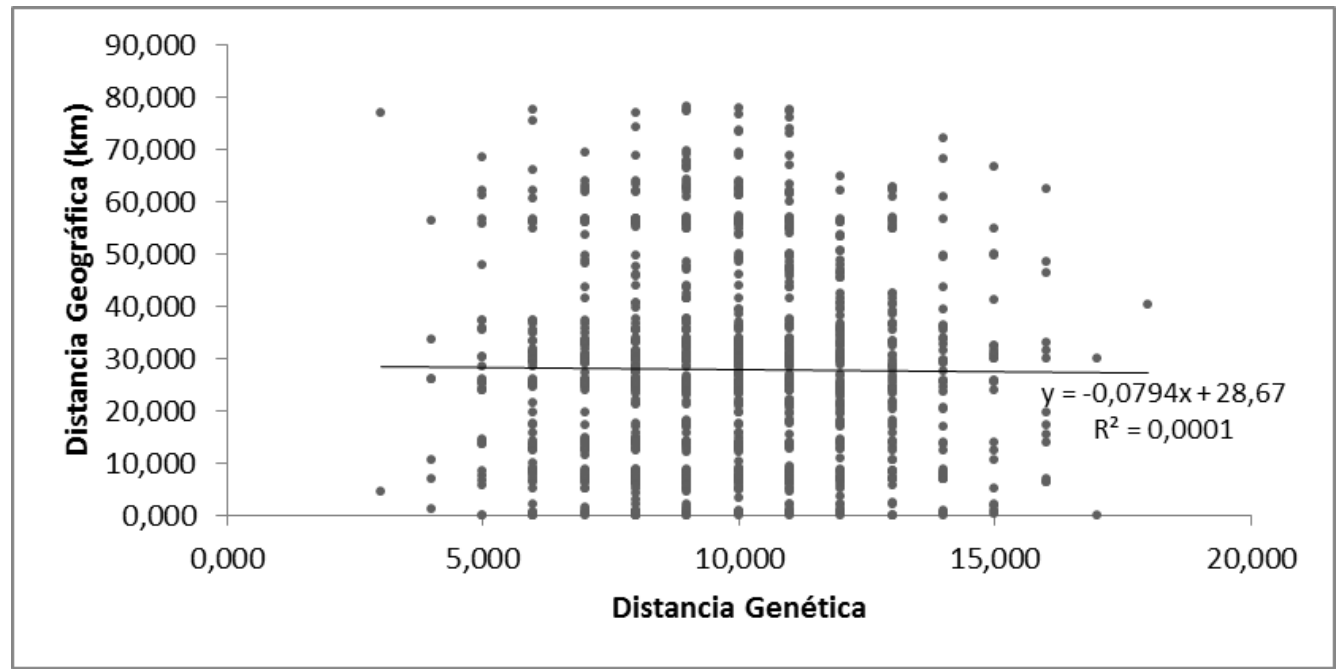

Figura 2. Relación entre distancia genética y distancia geográfica de 48 individuos de Prosopis chilensis.

Relationship between genetic distance and geographical distance of 48 individuals of Prosopis chilensis. 

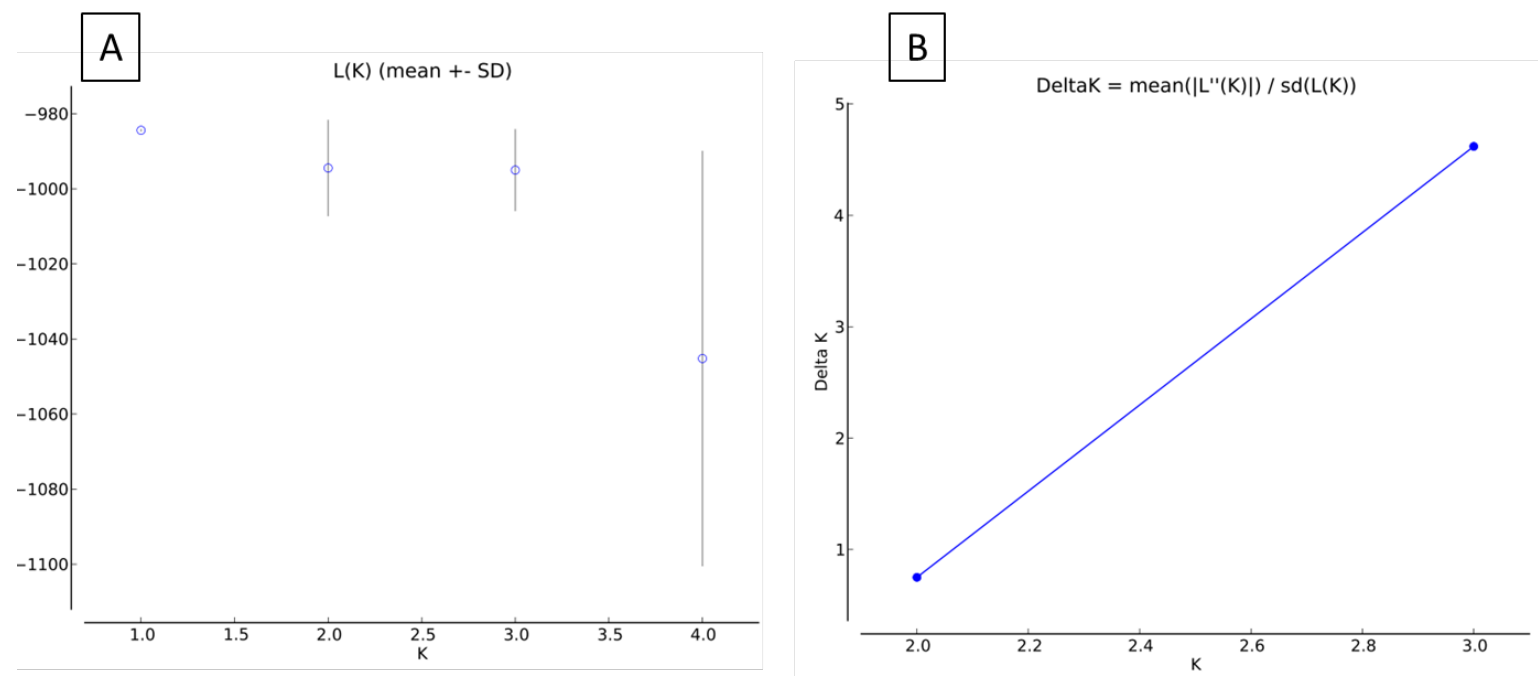

Figura 3: Relación de valores medios de probabilidad logarítmica L(K) (A) y Delta K (B) con valores K.

Relationship of log-likelihood mean values $\mathrm{L}(\mathrm{K})(\mathrm{A})$ and Delta $\mathrm{K}(\mathrm{B})$ with $\mathrm{K}$ values.

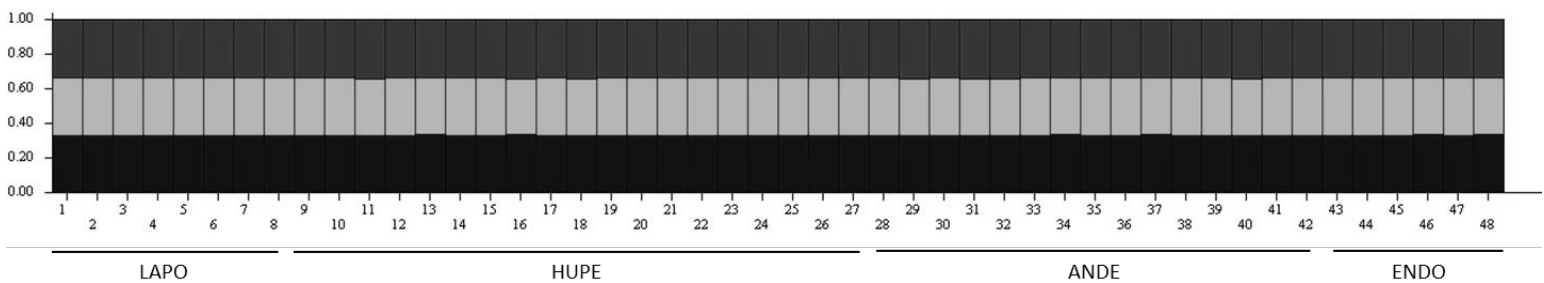

Figura 4. Representación de estructura de individuos de Prosopis chilensis de cuatro poblaciones (LAPO, HUPE, ANDE y ENDO) con un valor $\mathrm{K}=3$, realizado por el programa STRUCTURE.

Representation of the structure of Prosopis chilensis individuals from four populations (LAPO, HUPE, ANDE and ENDO) with a K $=3$ value, made by the STRUCTURE program.

Por otro lado, un mayor número de alelos privados (Ap) y un índice de Shannon (I) levemente mayor fue observado en las poblaciones de la Región Metropolitana (LAPO-HU$\mathrm{PE})$ que en poblaciones de la Región de Valparaíso (ANDEENDO). Así también se observa diferencias de diversidad genética entre la población LAPO $(\mathrm{He}=0,660)$, ubicada a menor altitud, y la población ENDO $(\mathrm{He}=0,632)$, ubicada a mayor altitud. Por lo tanto, la diversidad genética es levemente mayor en la zona baja (LAPO-HUPE) que en la zona alta (ANDE-ENDO). Así también, en poblaciones de la Región de Coquimbo, se encontraron diferencias de niveles de diversidad entre Elqui $(\mathrm{He}=0,52)$, Limarí $(\mathrm{He}=0,55)$ y Choapa $(\mathrm{He}=0,58)($ Monacada et al. 2019). $\mathrm{Al}$ igual que en nuestro estudio, se observó una situación similar en una especie arbórea forestal nativa que crece en la zona central de Chile, denominada Nothofagus glauca (Phil.) Krasser, especie que evidenció una mayor diversidad genética en los bosques de altitud baja (zona costera) que en bosques de mayor altitud (zona andina) (Muñoz et al. 2013). Sin embargo, de forma inversa, en poblaciones de $P$. alba localizadas en Bolivia, la población establecida a mayor altitud tuvo mayor variabilidad que la población a menor altitud (Bessega et al. 2018).

El nivel de diferenciación genética de $P$. chilensis $\left(\mathrm{F}_{\mathrm{ST}}\right.$ $=0,0015)$ entre las cuatro poblaciones (LAPO, HUPE, ANDE y ENDO) es baja, lo que concuerda con los resultados del análisis AMOVA (variación entre poblaciones = 0,$16 ; P=1,000$ ). Como la especie $P$. chilensis es de polinización cruzada, la buena circulación de polinizadores quizás permite el alto flujo de polen entre localidades de estas regiones y por ende un mayor flujo de genes. De hecho, las evidencias señalan que la especie $P$. chilensis es auto-incompatible, siendo obligatoria su fertilización cruzada, lo que aseguraría una alta recombinación genética y una amplia variación genética en las poblaciones (Hunziker et al. 1986). El alto flujo genético entre P. chilensis, P. flexuosa, P. alba y P. nigra ha dado como resultado una alta homogeneidad genética en especies de la sección $\mathrm{Al}$ - 
garobia, mostrando una baja diferenciación genética entre poblaciones y una alta variabilidad dentro de la población (Hunziker et al. 1986).

Al igual a la escasa diferenciación genética que se observa en el presente estudio, las estimaciones de variabilidad usando marcadores RAPD en poblaciones de P. chilensis, de acuerdo a los resultados de Ferreyra et al. (2010), indicaron que la mayor parte de la variabilidad genética se encontró dentro de las poblaciones, existiendo baja diferenciación entre poblaciones y regiones. Lo mismo fue observado con marcadores SSR en poblaciones de P. chilensis de la Región de Coquimbo (Moncada et al. 2019). Por otro lado, en Bolivia un estudio de caracterización genética de poblaciones de $P$. alba usando 10 loci SSR reveló que la mayor parte de variabilidad genética estuvo contenida dentro de los individuos (99\%), y se observó una baja diferenciación genética entre poblaciones (Bessega et al. 2018). Por otro lado, para evitar el aumento de riesgo de fragmentación, mermar la variabilidad genética e incrementar la endogamia, un estudio recomienda evitar el aislamiento de bosques pequeños (Bessega et al. 2017). Por lo tanto, la información genética capturada en nuestro trabajo a partir de poblaciones de Chacabuco y San Felipe, será útil para conducir planes de conservación y mejoramiento genético en $P$. chilensis.

El análisis STRUCTURE, la prueba de Mantel y el análisis multivariado EMD sugieren que todos los individuos de $P$. chilensis de las cuatro poblaciones son parte de un solo grupo, mostrando una sola estructura poblacional.

El análisis de prueba de Mantel ha revelado una muy baja correlación entre distancia genética y distancia geográfica entre poblaciones de P. chilensis, por lo tanto, se podría suponer que no hay aislación de poblaciones entre regiones, pudiendo inferirse que, dada la longevidad de la especie, podrían ser individuos remanentes de poblaciones originales. Por otro lado, el análisis con STRUCTURE ha revelado que la estructura genética de las poblaciones de $P$. chilensis no están afectadas geográficamente por barreras naturales o de actividad antrópica, ya que todas las poblaciones presentan la misma estructura. $\mathrm{Al}$ parecer la intensa actividad humana, la diferencia de altitud y la distancia geográfica, tanto de la Región Metropolitana y la Región de Valparaíso, no ha afectado la variabilidad genética de poblaciones de $P$. chilensis, llegando a presumir que no existen barreras naturales. Sin embargo, Valdivia y Romero (2013) detectaron que las próximas generaciones poblacionales juveniles de P. chilensis de Batuco y Huelpén (zona central de Chile) se verán reducidos progresivamente y contraídos, debido a la irrupción constante de la actividad humana (agricultura y residuos domiciliarios) y por efectos climáticos naturales, como el fenómeno de El Niño, entre otras causas.

Las localidades donde están establecidas las poblaciones de P. chilensis en este estudio, como la Provincia de Chacabuco y comunas de los Andes gozan de buen clima y moderada cobertura vegetacional, sin embargo, en el De- sierto de Atacama hay especies como P. tamarugo, a la cual se ha observado una baja variabilidad genética. Por otro lado, el cambio climático puede afectar la variabilidad genética de especies como P. chilensis y de especies acompañantes, tanto de flora como fauna y del bosque espinoso del cual forman parte. La conservación de la diversidad genética permite que las especies mantengan su potencial para adaptarse a cambios ambientales (Schierenbeck 2017). Se propone entonces buscar diversos grupos de genotipos, para mantener una amplia base genética de la especie. Ya existen algunos estudios que podrían orientar la conservación de ciertos atributos de la especie, como es el caso del estudio de Westphal et al. (2015), quienes identificaron variación de genotipos de distinta procedencia en respuesta a tratamientos de estrés salino, siendo más tolerantes los genotipos de la zona norte de Chile.

\section{CONCLUSIONES}

En conclusión, existe una moderada diversidad genética de poblaciones de $P$. chilensis entre zonas de menor altitud (LAPO y HUPE) y zonas de mayor altitud (ANDE y ENDO). Por otro lado, los marcadores microsatélites han evidenciado una escasa diferenciación genética entre poblaciones de $P$. chilensis de dos diferentes provincias de la zona central de Chile, presentando además la misma estructura genética. Por lo tanto, para efectos de ampliar los grupos genéticos de esta especie a nivel nacional, se requiere en el futuro continuar con los estudios y planes de conservación para salvaguardar el potencial adaptativo y evolutivo de la especie.

\section{AGRADECIMIENTOS}

Esta investigación fue financiada con fondos de la Universidad de Atacama, el Gobierno Regional de Atacama y el Instituto Forestal (INFOR).

\section{REFERENCIAS}

Aguilar DL, MC Acosta, MC Baranzelli, AN Sérsic, J DelatorreHerrera, A Verga, A Cosacov. 2020. Ecophylogeography of the disjunct South American xerophytic tree species Prosopis chilensis (Fabaceae). Biological Journal of the Linnean Society 129(4):793-809. DOI: https://doi.org/10.1093/biolinnean/blaa006

Bessega CF, CL Pometti, JT Miller, R Watts, BO Saidman, JC Vilardi. 2013. New microsatellite loci for Prosopis alba and P. chilensis (Fabaceae). Applications in Plant Sciences 1(5):1200324. DOI: https://doi.org/10.3732/apps.1200324

Bessega C, C Pometti, RP López, D Larrea-Alcázar, RH Fortunato, BO Saidman, JC Vilardi. 2018. Genetic diversity and differentiation among Prosopis alba (Leguminosae) populations from dry valleys of Bolivia with different levels of human disturbance and altitude. Ecology and Evolution 2018:1-13. DOI: https://doi.org/10.1002/ece3.4610

Bessega C, C Pometti, C Campos, BO Saidman, JC Vilardi. 2017. Implications of mating system and pollen dispersal indices 
for management and conservation of the semi-arid species Prosopis flexuosa (Leguminosae). Forest Ecology and Management 400:218-227. DOI: https://doi.org/10.1016/j.foreco.2017.06.007

Contreras R, V Porcile, F Aguayo. 2019. Microsatellites reveal a high genetic differentiation among native Geoffroea decorticans populations in Chilean Atacama Desert. Boletin de la Sociedad Argentina de Botánica 54(2):225-240. DOI: https://doi.org/10.31055/1851.2372.v54.n2.24367

Contreras R, F Carevic, V Porcile, M Arias. 2020. Development of SSR loci in Prosopis tamarugo Phillipi and assessment of their transferability to species of the Strombocarpa section. Forest Systems 29(2):e012. DOI: https://doi.org/10.5424/ fs/2020292-16706

Earl DA, BM Vonholdt. 2012. STRUCTURE HARVESTER: a website and program for visualizing STRUCTURE output and implementing the Evanno method. Conservation Genetic Resource 4: 359-361. DOI: https://doi.org/10.1007/ $\underline{\mathrm{s} 12686-011-9548-7}$

Excoffier L, G Laval, S Schneider. 2005. Arlequín ver. 3.0: An integrated software package for population genetics data analysis. Evolutionary Bioinformatics Online 1: 47-50. DOI: https://doi.org/10.1177/117693430500100003

Ferreyra LI, JC Vilardi, D Tosto, N Julio, BO Saidman. 2010 Adaptive genetic diversity and population structure of the "algarrobo" [Prosopis chilensis (Molina) Stuntz] analysed by RAPD and isozyme markers. European Journal of Forest Research 129:1011-1025. DOI: https://doi.org/10.1007/ $\underline{\mathrm{s} 10342-010-0386-\mathrm{Z}}$

González M, M Hormazabal, A Salinas. 2017. Efecto de técnicas de establecimiento sobre el desarrollo inicial de plantaciones de algarrobo (Prosopis chilensis (Mol.) Stuntz) en la zona central de Chile. Ciencia e Investigación Forestal. Instituto Forestal 23(2):43-56.

González EG. 2003. Microsatélites: sus aplicaciones en la conservación de la biodiversidad. Graeslisia 59(2-3):377-388. DOI: https://doi.org/10.3989/graellsia.2003.v59.i2-3.253

Goudet J. 2001. FSTAT, a program to estimate and test gene diversities and fixation indices, version 2.9.3. Consultado 29 julio 2019. Disponible en: http://www2.unil.ch/popgen/ softwares/fstat.htm

Hammer Ø, DAT Harper, PD Ryan. 2001. PAST: paleontological statistics software package for education and data analysis. Paleontología Electrónica. Consultado 3 ene. 2019. Disponible en: https://palaeo-electronica.org/2001 1/past/past.pdf

Hunziker JH, BO Saidman, CA Naranjo, RA Palacios, L Poggio, AD Burghardt. 1986. Hybridization and genetic variation of Argentine species of Prosopis. Forest Ecology and Management 16: 301-315. DOI: https://doi.org/10.1016/0378$\underline{1127(86) 90030-7}$
Moncada X, D Plaza, A Stoll, C Payacan, D Seelenfreund, E Martínez, A Bertin, FA Squeo. 2019. Genetic diversity and structure of the vulnerable species Prosopis chilensis (Molina) Stuntz in the Coquimbo Region, Chile. Gayana Botánica 76(1): 91-104. DOI: https://doi.org/10.4067/S071766432019000100091

Mottura MC, R Finkeldey, AR Verga, O Gailing. 2005. Development and characterization of microsatellite markers for Prosopis chilensis and Prosopis flexuosa and cross-species amplification. Molecular Ecology Notes 5:487-489. DOI: https://doi.org/10.1111/j.1471-8286.2005.00965.x

Muñoz F, C Muñoz, M Uribe, MA Martín, JR Molina, MA Herrera, JB Álvarez, LM Martín. 2013. Composition, structure and diversity of populations of Nothofagus glauca located in the Mediterranean zone of Chile. Gayana Botánica 70: 82-91. DOI: https://doi.org/10.4067/S0717-66432013000100009

Peakall R, PE Smouse. 2012. GenAlEx 6.5. Bioinformatics 28:2537-2539. DOI: https://doi.org/10.1093/bioinformatics/bts 460

Pritchard JK, M Stephens, P Donnelly. 2000. Inference of population structure using multilocus genotype data. Genetics 155: 945-959.

Schierenbeck KA. 2017. Population-level genetic variation and climate change in a biodiversity hotspot. Annals of Botany 119: 215-228. DOI: https://doi.org/10.1093/aob/mcw214

Valdivia C, C Romero. 2013. En la senda de la extinción: el caso del algarrobo Prosopis chilensis (Fabaceae) y el bosque espinoso en la Región Metropolitana de Chile central. Gayana Botánica 70(1):57-65. DOI: https://doi.org/10.4067/ $\underline{\mathrm{S} 0717-66432013000100007}$

Van Oosterhout C, WF Hutchinson, DPM Wills, P Shipley. 2004. MICRO-CHECKER: software for identifying and correcting genotyping errors in microsatellite data. Molecular Ecology 4: 535-538, DOI: https://doi.org/10.1111/j.1471$\underline{8286.2004 .00684 . x}$

Verzino G, C Carrranza, M Ledesma, M Joseau, J DiRienzo. 2003. Adaptive genetic variation of Prosopis chilensis (Mol) Stuntz: Preliminary results from one test-site. Forest Ecology and Management 175:119-29. DOI: https://doi. org/10.1016/S0378-1127(02)00124-X

Walter K. 2011. Prosopis, an alien among the sacred trees of South India. University of Helsinki Tropical Forestry Reports 38. Consultado 29 jul. 2019. Disponible en: https:// helda.helsinki.fi/bitstream/handle/10138/24969/prosopis. pdf?sequence $=1$

Westphal C, P Gachón, J Bravo J, et al. 2015. The potential of Algarrobo (Prosopis chilensis (Mol.) Stuntz) for regeneration of desertified soils: assessing seed germination under saline conditions. Environmental Management 56:209-220. DOI: https://doi.org/10.1007/s00267-015-0490-4 


\section{APÉNDICE}

Apéndice 1. Coordenadas geográficas de 48 individuos de Prosopis chilensis.

\begin{tabular}{|c|c|c|c|c|}
\hline $\mathrm{N}^{\circ}$ Muestra & Provincia & Latitud & Longitud & Altitud \\
\hline 1 & Chacabuco & $33^{\circ} 16^{\prime} 17.371^{\prime \prime} \mathrm{S}$ & $70^{\circ} 53^{\prime} 23.342^{\prime \prime} \mathrm{W}$ & 475 \\
\hline 2 & Chacabuco & $33^{\circ} 15^{\prime} 56.568^{\prime \prime} \mathrm{S}$ & $70^{\circ} 53^{\prime} 37.811^{\prime \prime} \mathrm{W}$ & 483 \\
\hline 5 & Chacabuco & $33^{\circ} 15^{\prime} 39.836^{\prime \prime} \mathrm{S}$ & $70^{\circ} 53^{\prime} 36.484^{\prime \prime} \mathrm{W}$ & 497 \\
\hline 12 & Chacabuco & $33^{\circ} 9^{\prime} 45.523^{\prime \prime} \mathrm{S}$ & $70^{\circ} 53^{\prime} 37.888^{\prime \prime} \mathrm{W}$ & 529 \\
\hline 16 & Chacabuco & $33^{\circ} 11^{\prime} 26.214 ” \mathrm{~S}$ & $70^{\circ} 52^{\prime} 45.457^{\prime \prime} \mathrm{W}$ & 520 \\
\hline 18 & Chacabuco & $33^{\circ} 11^{\prime} 0.447^{\prime \prime} \mathrm{S}$ & $70^{\circ} 52^{\prime} 34.019^{\prime \prime} \mathrm{W}$ & 522 \\
\hline 23 & Chacabuco & $33^{\circ} 8,37.527^{\prime \prime} \mathrm{S}$ & $70^{\circ} 51 ' 7.694 " \mathrm{~W}$ & 541 \\
\hline 25 & Chacabuco & $33^{\circ} 8,39.837 " \mathrm{~S}$ & $70^{\circ} 51^{\prime} 2.995 ” \mathrm{~W}$ & 541 \\
\hline 26 & Chacabuco & $33^{\circ} 5^{\prime} 6.631^{\prime \prime} \mathrm{S}$ & $70^{\circ} 47^{\prime} 54.716^{\prime \prime} \mathrm{W}$ & 553 \\
\hline 27 & Chacabuco & $33^{\circ} 5^{\prime} 6.745^{\prime \prime} \mathrm{S}$ & $70^{\circ} 47^{\prime} 53.523^{\prime \prime} \mathrm{W}$ & 572 \\
\hline 28 & Chacabuco & $33^{\circ} 5^{\prime} 6.267^{\prime \prime} \mathrm{S}$ & $70^{\circ} 47^{\prime} 55.172 ” \mathrm{~W}$ & 573 \\
\hline 30 & Chacabuco & $33^{\circ} 5^{\prime} 6.168^{\prime \prime} \mathrm{S}$ & $70^{\circ} 48^{\prime} 4.271^{\prime \prime} \mathrm{W}$ & 572 \\
\hline 31 & Chacabuco & $33^{\circ} 5^{\prime} 10.282^{\prime \prime} \mathrm{S}$ & $70^{\circ} 48^{\prime} 0.4211^{\prime \prime} \mathrm{W}$ & 574 \\
\hline 32 & Chacabuco & $33^{\circ} 5^{\prime} 31.916^{\prime \prime} \mathrm{S}$ & $70^{\circ} 43^{\prime} 54.477^{\prime \prime} \mathrm{W}$ & 624 \\
\hline 33 & Chacabuco & $33^{\circ} 5^{\prime} 31.412^{\prime \prime} \mathrm{S}$ & $70^{\circ} 43^{\prime} 55.701 ” \mathrm{~W}$ & 624 \\
\hline 34 & Chacabuco & $33^{\circ} 5^{\prime} 31.666^{\prime \prime} \mathrm{S}$ & $70^{\circ} 43^{\prime} 51.386^{\prime \prime} \mathrm{W}$ & 624 \\
\hline 36 & Chacabuco & $33^{\circ} 5^{\prime} 31.883^{\prime \prime} \mathrm{S}$ & $70^{\circ} 43^{\prime} 38.084^{\prime \prime} \mathrm{W}$ & 629 \\
\hline 37 & Chacabuco & $33^{\circ} 5^{\prime} 32.592^{\prime \prime} \mathrm{S}$ & $70^{\circ} 43^{\prime} 31.425^{\prime \prime} \mathrm{W}$ & 632 \\
\hline 38 & Chacabuco & $33^{\circ} 8,49.789^{\prime \prime} \mathrm{S}$ & $70^{\circ} 39^{\prime} 35.417^{\prime \prime} \mathrm{W}$ & 719 \\
\hline 39 & Chacabuco & $33^{\circ} 8,29.224^{\prime \prime} \mathrm{S}$ & $70^{\circ} 39^{\prime} 43.713^{\prime \prime} \mathrm{W}$ & 716 \\
\hline 41 & Chacabuco & $33^{\circ} 8^{\prime} 9.7 " \mathrm{~S}$ & $70^{\circ} 39^{\prime} 59.128^{\prime \prime} \mathrm{W}$ & 702 \\
\hline 42 & Chacabuco & $33^{\circ} 8,41.966^{\prime \prime} \mathrm{S}$ & $70^{\circ} 40^{\prime} 9.348^{\prime \prime} \mathrm{W}$ & 698 \\
\hline 43 & Chacabuco & $33^{\circ} 8^{\prime} 41.995^{\prime \prime} \mathrm{S}$ & $70^{\circ} 39^{\prime} 50.167^{\prime \prime} \mathrm{W}$ & 705 \\
\hline 45 & Chacabuco & $33^{\circ} 5^{\prime} 26.527^{\prime \prime} \mathrm{S}$ & $70^{\circ} 39^{\prime} 7.41 ” \mathrm{~W}$ & 819 \\
\hline 46 & Chacabuco & $33^{\circ} 5^{\prime} 26.056^{\prime \prime} \mathrm{S}$ & $70^{\circ} 39^{\prime} 6.167^{\prime \prime} \mathrm{W}$ & 820 \\
\hline 48 & Chacabuco & $33^{\circ} 5^{\prime} 25.376^{\prime \prime} \mathrm{S}$ & $70^{\circ} 39^{\prime} 8.507^{\prime \prime} \mathrm{W}$ & 815 \\
\hline 49 & Chacabuco & $33^{\circ} 5^{\prime} 25.658^{\prime \prime} \mathrm{S}$ & $70^{\circ} 39^{\prime} 9.322^{\prime \prime} \mathrm{W}$ & 813 \\
\hline 56 & San Felipe & $32^{\circ} 52^{\prime} 33.152^{\prime \prime} \mathrm{S}$ & $70^{\circ} 38^{\prime} 34.55^{\prime \prime} \mathrm{W}$ & 779 \\
\hline 57 & San Felipe & $32^{\circ} 52^{\prime} 40.89^{\prime \prime} \mathrm{S}$ & $70^{\circ} 38^{\prime} 31.269^{\prime \prime} \mathrm{W}$ & 778 \\
\hline 58 & San Felipe & $32^{\circ} 52^{\prime} 40.266^{\prime \prime} \mathrm{S}$ & $70^{\circ} 37^{\prime} 14.686^{\prime \prime} \mathrm{W}$ & 803 \\
\hline 59 & San Felipe & $32^{\circ} 52^{\prime} 40.083^{\prime \prime} \mathrm{S}$ & $70^{\circ} 37^{\prime} 13.798^{\prime \prime} \mathrm{W}$ & 802 \\
\hline 60 & San Felipe & $32^{\circ} 52^{\prime} 40.058^{\prime \prime} \mathrm{S}$ & $70^{\circ} 37^{\prime} 13.182 ” \mathrm{~W}$ & 801 \\
\hline 61 & San Felipe & $32^{\circ} 52^{\prime} 39.976^{\prime \prime} \mathrm{S}$ & $70^{\circ} 37^{\prime} 12.026^{\prime \prime} \mathrm{W}$ & 803 \\
\hline 65 & San Felipe & $32^{\circ} 49^{\prime} 59.14^{\prime \prime} \mathrm{S}$ & $70^{\circ} 34^{\prime} 4.846^{\prime \prime} \mathrm{W}$ & 875 \\
\hline 66 & San Felipe & $32^{\circ} 49^{\prime} 43.12^{\prime \prime} \mathrm{S}$ & $70^{\circ} 34^{\prime} 3.218^{\prime \prime} \mathrm{W}$ & 882 \\
\hline 67 & San Felipe & $32^{\circ} 49^{\prime} 58.94 ” \mathrm{~S}$ & $70^{\circ} 34^{\prime} 5.266^{\prime \prime} \mathrm{W}$ & 874 \\
\hline 68 & San Felipe & $32^{\circ} 53$ ' 13.724" S & $70^{\circ} 31^{\prime} 48.811^{\prime \prime} \mathrm{W}$ & 1097 \\
\hline
\end{tabular}


Apéndice 1. Continuación

\begin{tabular}{|c|c|c|c|c|}
\hline 70 & San Felipe & $32^{\circ} 53^{\prime} 14.749$ ” S & $70^{\circ} 31 ’ 49.982 ” \mathrm{~W}$ & 1097 \\
\hline 74 & San Felipe & $32^{\circ} 52^{\prime} 18.456^{\prime \prime} \mathrm{S}$ & $70^{\circ} 41^{\prime} 45.808^{\prime \prime} \mathrm{W}$ & 747 \\
\hline 76 & San Felipe & $32^{\circ} 52^{\prime} 18.179^{\prime \prime} \mathrm{S}$ & $70^{\circ} 41^{\prime} 47.072^{\prime \prime} \mathrm{W}$ & 747 \\
\hline 78 & San Felipe & $32^{\circ} 51^{\prime} 48.018^{\prime \prime} \mathrm{S}$ & $70^{\circ} 41^{\prime} 37.342^{\prime \prime} \mathrm{W}$ & 739 \\
\hline 79 & San Felipe & $32^{\circ} 52^{\prime} 3.126^{\prime \prime} \mathrm{S}$ & $70^{\circ} 41^{\prime} 43.785^{\prime \prime} \mathrm{W}$ & 744 \\
\hline 80 & San Felipe & $32^{\circ} 34^{\prime} 52.855^{\prime \prime} \mathrm{S}$ & $70^{\circ} 42^{\prime} 0.783^{\prime \prime} \mathrm{W}$ & 925 \\
\hline 81 & San Felipe & $32^{\circ} 34^{\prime} 58.535^{\prime \prime} \mathrm{S}$ & $70^{\circ} 42^{\prime} 5.722^{\prime \prime} \mathrm{W}$ & 921 \\
\hline 82 & San Felipe & $32^{\circ} 35^{\prime} 5.503 " \mathrm{~S}$ & $70^{\circ} 42^{\prime} 11.453^{\prime \prime} \mathrm{W}$ & 914 \\
\hline 83 & San Felipe & $32^{\circ} 35^{\prime} 11.703^{\prime \prime S}$ & $70^{\circ} 42^{\prime} 16.365^{\prime \prime} \mathrm{W}$ & 911 \\
\hline 84 & San Felipe & $32^{\circ} 35^{\prime} 22.417^{\prime \prime} \mathrm{S}$ & $70^{\circ} 42^{\prime} 28.38^{\prime \prime} \mathrm{W}$ & 900 \\
\hline 86 & San Felipe & $32^{\circ} 35^{\prime} 51.47^{\prime \prime} \mathrm{S}$ & $70^{\circ} 42^{\prime} 50.335^{\prime \prime} \mathrm{W}$ & 885 \\
\hline
\end{tabular}

